Original Research Article

\title{
Utilization pattern of antiepileptic drugs and their adverse effects in tertiary healthcare and teaching hospital
}

\author{
Yogesh B. Magar, Rajesh S. Hiray*, Balasaheb B. Ghongane
}

Department of Pharmacology, Byramjee Jeejeebhoy Government Medical College, Pune, Maharashtra, India

Received: 28 November 2018 Accepted: 12 December 2018

*Correspondence to:

Dr. Rajesh S. Hiray,

Email: rajesh.hiray@gmail.com

Copyright: (c) the author(s), publisher and licensee Medip Academy. This is an openaccess article distributed under the terms of the Creative Commons Attribution NonCommercial License, which permits unrestricted noncommercial use, distribution, and reproduction in any medium, provided the original work is properly cited.

\begin{abstract}
Background: Epilepsy is the most common neurological condition with 65 million cases of active epilepsy found worldwide. The incidence is approximately $0.3-0.5 \%$ in different world populations with a prevalence rate of five to ten per thousand people. The aim of the present study was to evaluate the prescriptions according to WHO/INRUD drug use indicators and to study the adverse effects to antiepileptic drugs (AEDs).

Methods: A cross sectional survey based observational study of 1year duration was conducted at tertiary healthcare hospital. Prescription data of patients $(n=361)$ with Epilepsy from Neurology department was analysed using WHO indicators. The demographic data, type of seizures, AEDs prescribed and adverse drug reactions (ADRs) reported by the patients were recorded. Statistical analysis was done using Microsoft excel 2013.

Results: A total of 593 AEDs were prescribed to 361 patients. Average number of AEDs prescribed per prescription was $1.65 \pm 0.78$ (S.D) with only $02 \%$ of newer AEDs. Generalized Tonic Clonic (GTC) was the most common seizure with $55.68 \%$. Phenytoin (32\%) was commonly prescribed followed by valproate for GTCS. Carbamazepine was commonly prescribed for partial seizures. Out of 15 ADR cases that has been recorded, phenytoin $(73 \%)$ was associated with most ADRs followed by valproate (20\%). $53 \%$ patients were on Monotherapy, $31 \%$ on dual drug therapy.

Conclusions: Older AEDs are still commonly prescribed drugs. Prescription of newer AEDs to be encouraged, as study revealed majority of adverse effects to drugs like phenytoin and valproate. Study concludes the need of creating awareness of reporting of adverse event to AEDs, in treating physician.
\end{abstract}

Keywords: Anti-epileptic drugs, Adverse drug reaction, Utilisation pattern, WHO indicators

\section{INTRODUCTION}

Epilepsy describes a condition in which a person has recurrent seizures due to a chronic, underlying process. It refers to a clinical phenomenon rather than a single disease unit, since there are numerous forms and causes of epilepsy. ${ }^{1}$ Epilepsy is a common neurological disorder which demands immediate medical attention and often long-term therapy. The incidence is approximately 0.3 $0.5 \%$ in different world populations with a prevalence rate of five to ten per thousand people. It is the most common neurological condition worldwide with Indian prevalence of $572.8 / 100,000$ population/year. ${ }^{2}$ This figure shows rising trends as treatment gaps for active epilepsy exceeded $75 \%$ in most low-income countries. ${ }^{3}$

The overall aim in treating epilepsy should be complete control of seizures, without causing any untoward reaction due to the medication. A large number of drugs are currently available for the treatment of epilepsy. Older/conventional drugs like Phenytoin, Carbamazepine, Sod. valproic acid and Phenobarbitone are commonly used as first line drugs. They are relatively less expensive than the newer anti-epileptics but have serious side effect. Drugs like levetiracetam, gabapentin, lamotrigine, vigabatrin, topiramate, lacosamide and zonisamide are the newer ones and currently used as add-on or alternative 
therapy. They have lesser adverse effects and have few, if any, drug interactions. ${ }^{4,5}$ Studies have shown that, older antiepileptic drug like phenytoin and Valproate are predominantly used as first line therapy. ${ }^{6,7}$

Some side effects may be common with the abovementioned drugs and include sedation and ataxia. They can be diverse as well, ranging from idiosyncratic reactions like bone marrow depression (carbamazepine) to acute myopia and glaucoma (topiramate). Monotherapy is the usual dictum, but polytherapy is needed for patients with multiple seizure types or refractory disease. ${ }^{8-10}$

The current study will attempt to analyse the pattern of drug utilization in different types of epilepsy and prescriptions will be evaluated for completeness in relation to dose, duration, frequency and WHO/INRUD (World Health Organization/ International Network of Rational Use of Drugs indicators). The extent of polytherapy will also be looked into. The adverse drug reactions reported by the patients and their impact on the continuation of antiepileptic therapy will be evaluated.

\section{METHODS}

A cross sectional survey based observational study was conducted at Department of Medicine of tertiary healthcare and teaching hospital, from December 2015 to November 2016. Patients visiting Department of General Medicine (Neurology) of tertiary care teaching hospital, were screened for the study and subjects who satisfy the inclusion and exclusion criteria mentioned below were recruited for the study.

\section{Inclusion criteria}

- Diagnosed cases of epilepsy (GTC, SPS and CPS) on antiepileptic medications

- Patients attending neurology department of Medicine of all ages of either sex receiving antiepileptics in any form (i.e. oral or parenteral).

\section{Exclusion criteria}

- Patients not willing to be part of the study or refusing to sign Informed Consent Form

- Patients with major neurologic disabilities such as mental retardation, aphasia, or motor deficits.

\section{Detailed research plan}

A cross sectional, observational study was conducted for a period of twelve months from December 2015 to November 2016 in 361 epileptic patients visiting department of Medicine, after taking official permission from above mentioned department and after approval from Institutional Ethical committee (IEC). The data were collected from medical case sheet/or prescription given to patients.
The data were collected on a case record form (CRF) designed for study, includes: demographic details of patients, any comorbidity present in patients, details of Antiepileptic Drugs (AEDs) and non-AEDs (supplementary drugs) used for management of epilepsy including dose, frequency of administration, and duration of therapy etc.

Prescription data also has been elaborated for following parameters

Type and distribution of seizure frequency, observed drug prescription pattern, various combination drug therapies used, WHO/INRUD drug use indicators, Anatomic Therapeutic Chemical (ATC) classification of AEDs with Prescribed Daily Dose (PDD) and Defined Daily Dose (DDD) with PDD/DDD ratio analysis, Details of Adverse drug event/s as per CDSCO/PVPI form, with description of reaction/problem, seriousness of the reaction, and causality assessment by Naranjo's algorithm etc.

Data retrieved from case record forms were entered in Microsoft Excel sheet and assessed for various parameters to find out study objectives.

\section{Statistical analysis}

For the statistical analysis mean, percentages and standard deviation (SD) were calculated by using Microsoft Excel 2013.

\section{RESULTS}

Data of total 361 epileptic patients were analysed. Majority of the patient i.e. $185(51 \%)$ patients were from the age group 21-40years while $90(25 \%)$ participants belonged to age group 41-60years. Only $41(11 \%)$ patients were in the age group $\geq 61$ years. In all $55 \%$ were males and $45 \%$ were females (Table 1).

Table 1: Age range, gender wise distribution in Epileptic patients.

\begin{tabular}{|llll|}
\hline $\begin{array}{l}\text { Age range } \\
(\text { years) }\end{array}$ & Male $(\%)$ & $\begin{array}{l}\text { Female } \\
(\%)\end{array}$ & Total $(\%)$ \\
\hline $1-20$ & $30(9 \%)$ & $15(4 \%)$ & $45(13 \%)$ \\
\hline $21-40$ & $95(26 \%)$ & $90(25 \%)$ & $185(51 \%)$ \\
\hline $41-60$ & $56(16 \%)$ & $34(9 \%)$ & $90(25 \%)$ \\
\hline$\geq 61$ & $16(4 \%)$ & $25(7 \%)$ & $41(11 \%)$ \\
\hline Total & $197(55 \%)$ & $164(45 \%)$ & $361(100 \%)$ \\
\hline
\end{tabular}

The number of epileptic patients with co-morbidity were $30 \%$, whereas $70 \%$ were didn't have any comorbidity. Most common comorbidity associated with epilepsy was hypertension $44(12.18 \%)$ number of patients followed by cerebrovascular accidents $19(05.26 \%)$ of epileptic patients. Other common comorbidities found in these patients were ischemic heart disease $16(04.43 \%)$, anemia $14(03.87 \%)$, whereas diabetes mellitus 11 (03\%), 
dyslipidemia $11(03 \%)$ and TB meningitis $8(02.21 \%)$ were also noticed as occasional comorbidities. Rarely, psychosis, HIV- ICS, rheumatic valvular heart disease, and hypothyroidism was noted (Figure 1).

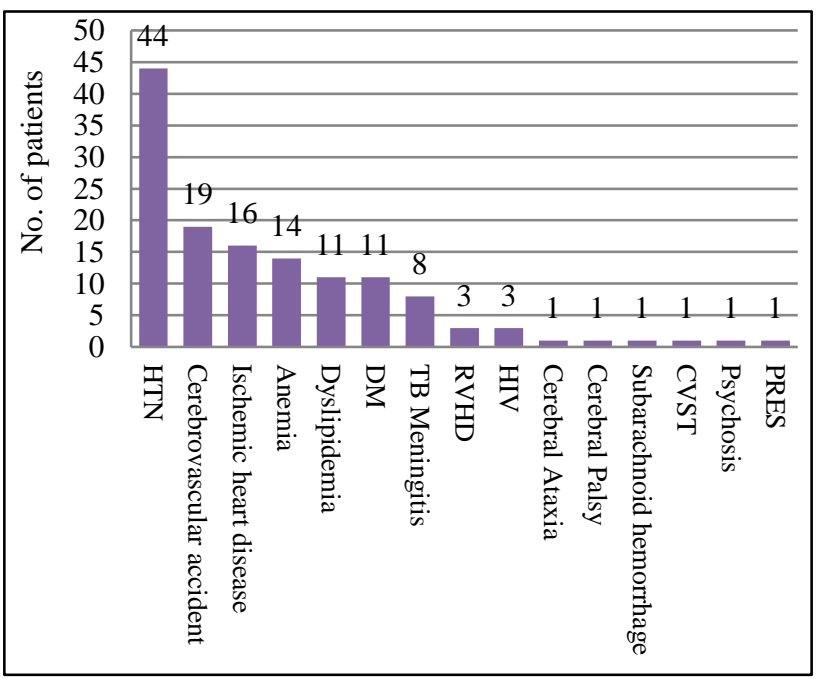

Figure 1: Distribution of comorbidities in epilepsy patients.

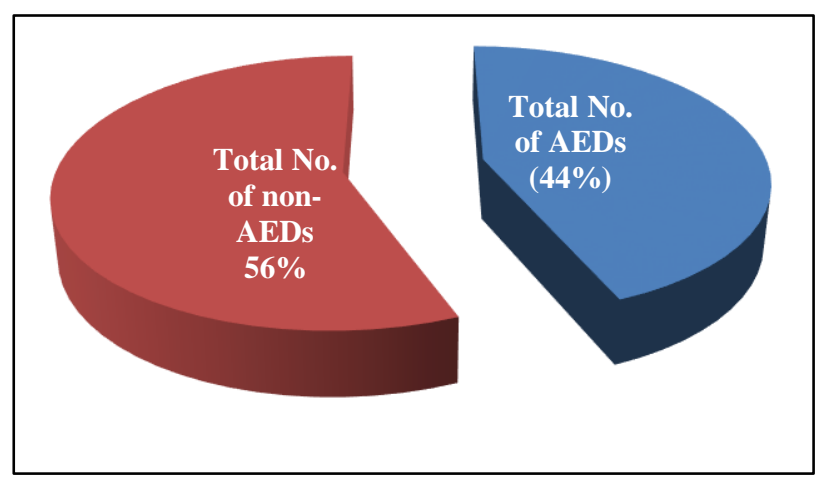

Figure 2: Percent distribution of total drug use.

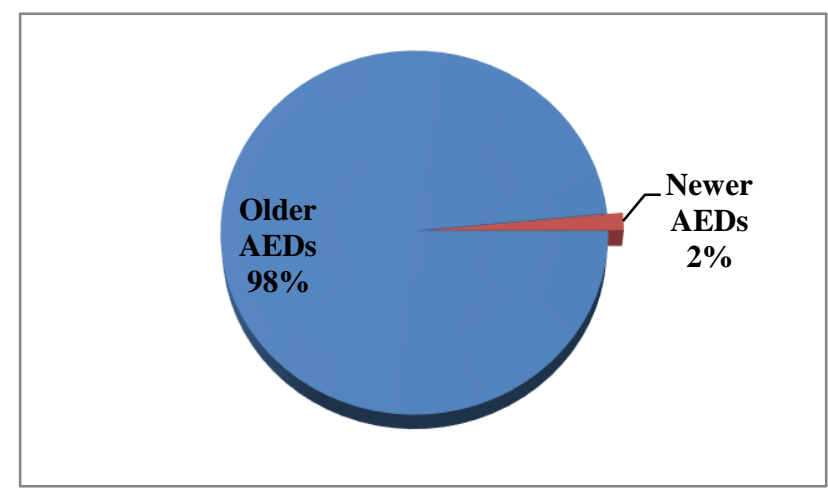

Figure 3: Percentage distribution of older and newer Anti-epileptic drugs.

\section{Prescription data}

Generalized seizures were noted in $227(62.88 \%)$ patients of whom, Generalised Tonic- Clonic Seizure (GTCS) was most common type of seizure encountered. It was seen in $201(55.68 \%)$ patients, followed by Absent Seizures (AS) 14(4\%), Secondary Generalized Seizures (SGS) 7(2\%), Myoclonic Seizures (MS) 2, Tonic Seizures (TS) 2, and Juvenile Myoclonic Seizures (JMS) 1.

Focal seizures seen in 127 (35.18\%) patients of whom, Simple Partial Seizure (SPS) encountered in 49 (14\%) of patients followed by Complex Partial Seizure (CPS) 39 (11\%), Simple Febrile Seizures (SFS) 15 (4\%), Complex Febrile Seizures (CFS) 23 (6\%), Post-Partum Epilepsy (PPE) 1, epileptic spasm 1.

Unclassified seizures like refractory seizures was seen in only 1 patient.

Total number of drugs accounted were 1354. Out of which, total number of anti-epileptic drugs (AEDs) used were 593 $(44 \%)$ and total number of non-AEDs or supplementary drugs used were $761(56 \%$ ) (Figure 2 ). Only $2 \%$ of AEDs prescribed were newer ones and rest $98 \%$ were older AEDs (Figure 3).

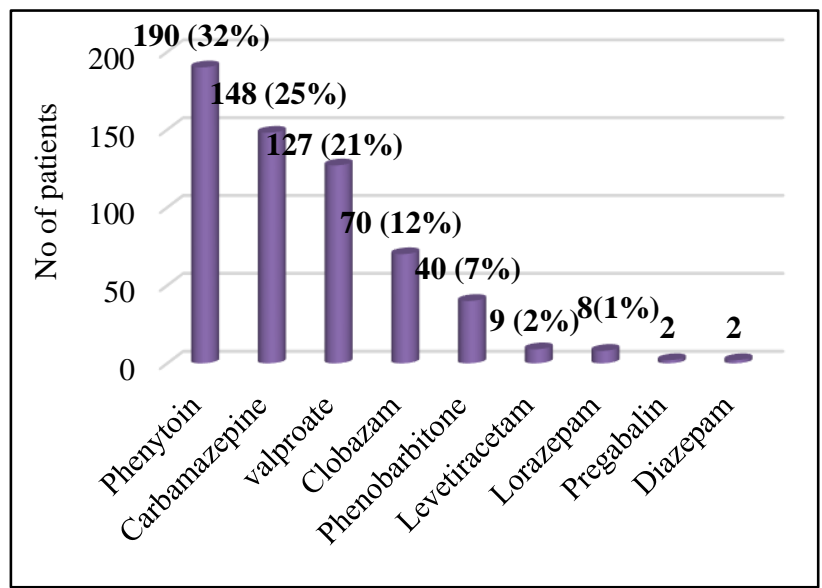

Figure 4: Percent distribution of anti-epileptic drug use.

Phenytoin was the most common drug which was prescribed in 190 (32\%) of epileptic patients, followed carbamazepine, $2^{\text {nd }}$ most common AED prescribed in 148 $(25 \%)$ of epilepsy patients.

The $3^{\text {rd }}$ most common drug prescribed to an epileptic patient was valproate prescribed in 127 (21.3\%) of patients. Other AEDs used are as follows: clobazam, 70 (11.7\%); phenobarbitone, $40(6.71 \%)$; levetiracetam, 09 (1.54\%); lorazepam, 08 (1.34\%); pregabalin, 02 (0.34\%); diazepam, $02(0.34 \%)$ (Figure 4$)$.

Supplementary drugs which were prescribed in total was 761. Of 761, the pie diagram shows supplementary drug which was most commonly prescribed was folic acid 259 (34\%), followed by MVBC 84 (11\%), ferrous sulphate + folate combination $35(4.6 \%)$, calcium lactate $34(4.5 \%)$ etc. (Figure 5). 


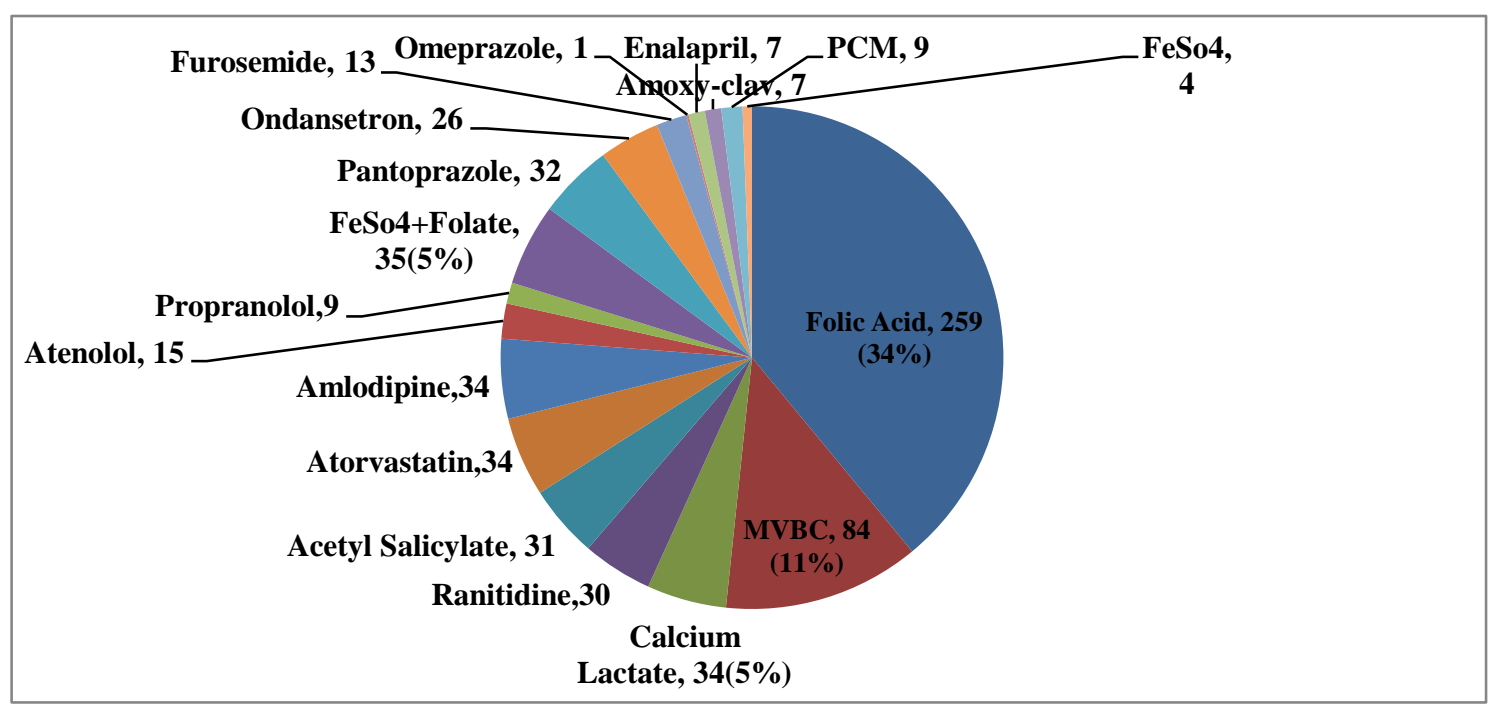

Figure 5: Percent distribution of non- anti-epileptic/supplementary drug use.

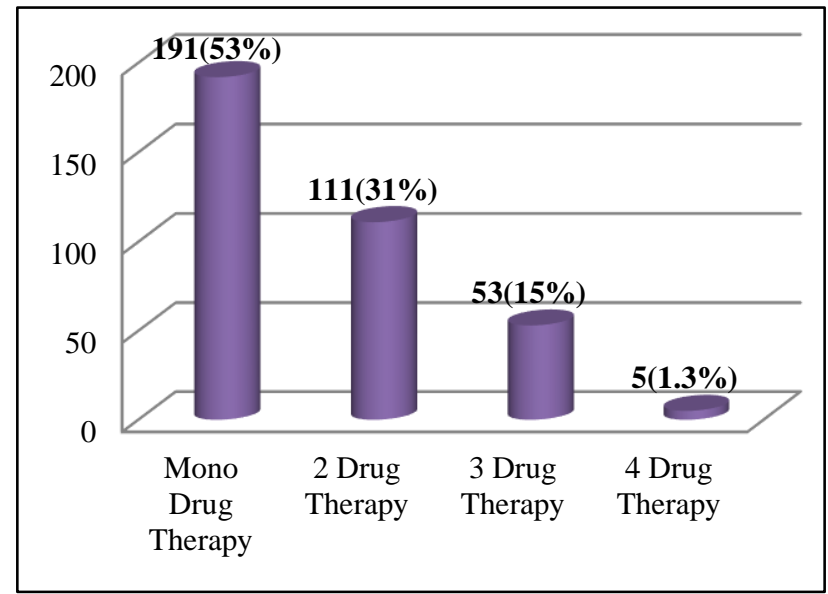

Figure 6: Patients according to no. of AEDs prescribed in epilepsy.

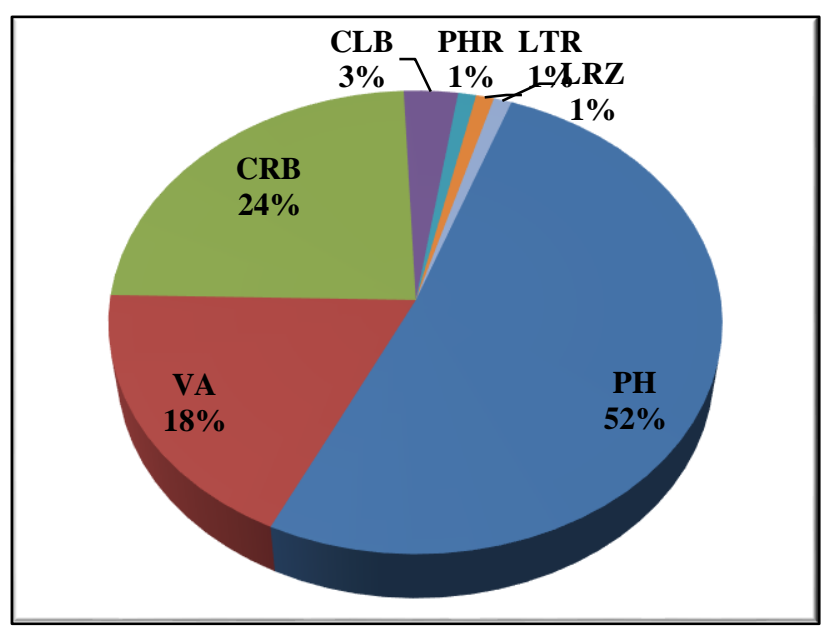

Figure 7: Distribution of mono drug therapy in epilepsy patients.

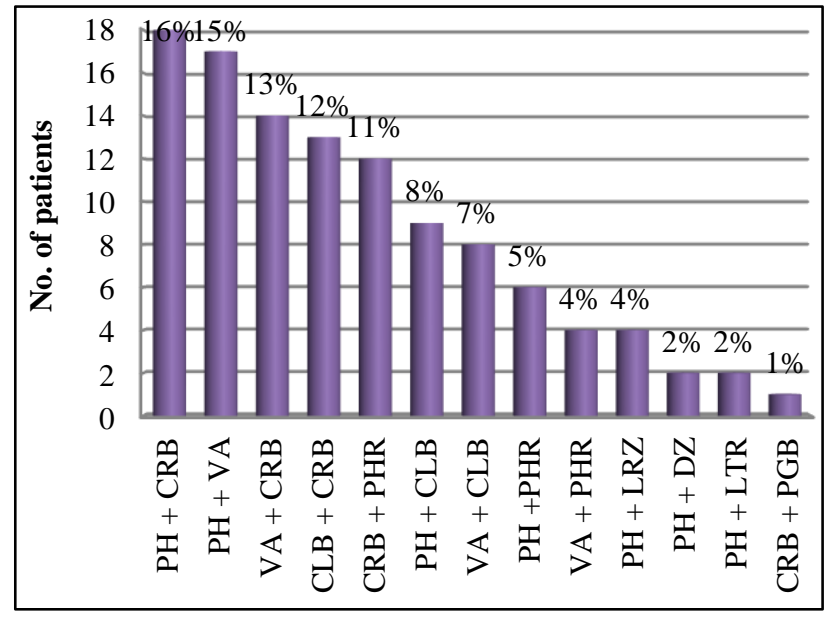

Figure 8: Distribution of 2 drug combination therapy in epilepsy patients.

Various drug combination therapy used has been demonstrated (Figure 6-10).

Prescriptions were assessed by using WHO/INRUD prescribing indicators as follows.

\section{WHO prescribing indicators}

- Average no. of drugs per encounter in epilepsy patients -3.75

- Average no. of antiepileptic drugs (AEDs) per encounter in epilepsy patients- 1.64

- Percentage of drugs prescribed by generic name in epilepsy- $99.70 \%$.

- Percentage of drugs prescribed from National List of Essential Medicine 2015, in epilepsy patients - 100\% 


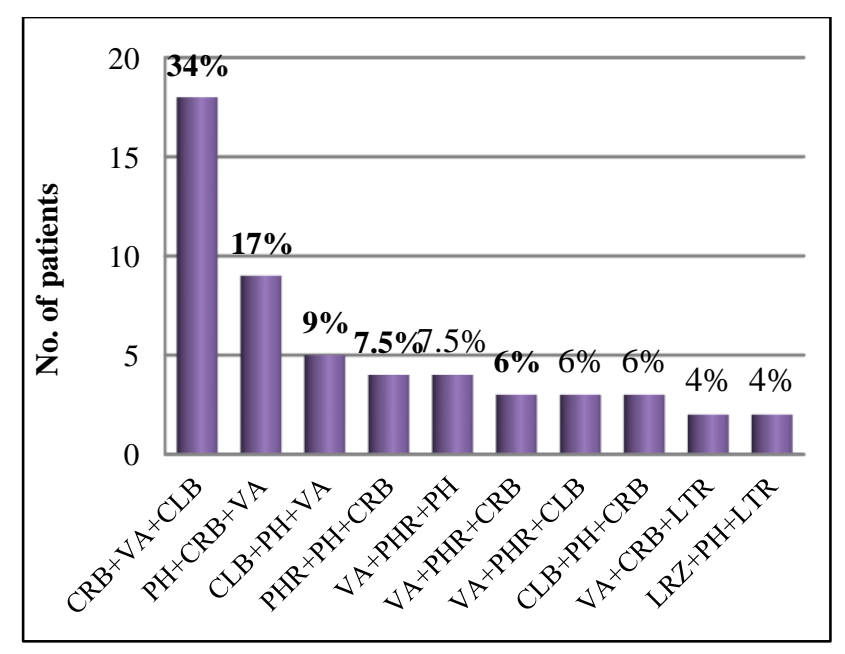

Figure 9: Distribution of 3 drug combination therapy in epilepsy patients.

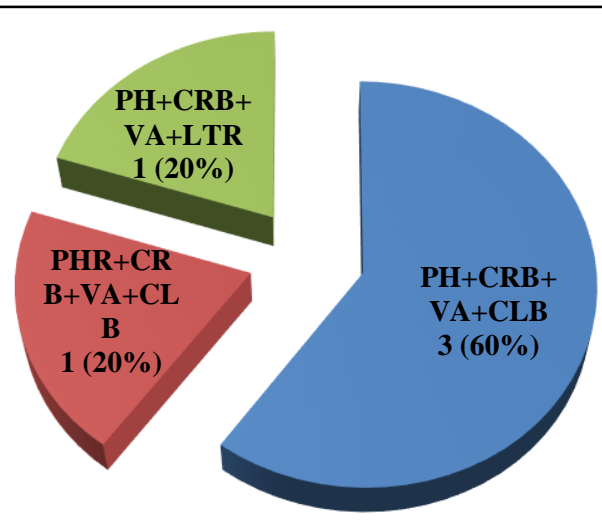

Figure 10: Distribution of 4 drug combination therapy in epilepsy patients.

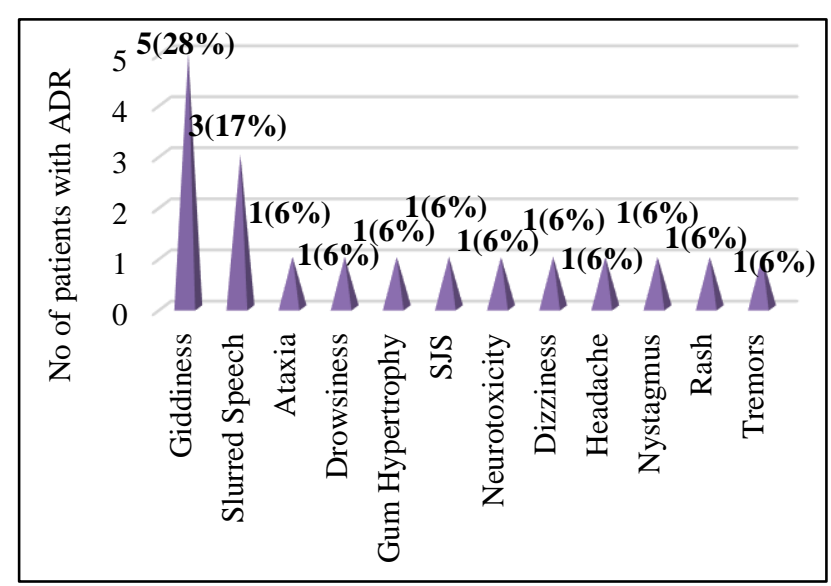

Figure 11: Distribution of ADRs amongst epilepsy patients.

\section{Prescriptions were further analyzed for the following}

- Percentage of encounters with multivitamins prescribed in epilepsy patients- $23.26 \%$
- $\quad$ Percentage of encounters with folic acid prescribed in epilepsy patients $-71.74 \%$

Out of total 15 cases most adverse drug event (ADE) was associated with phenytoin in $11(73 \%)$ of cases followed by valproate $03(20 \%)$ and carbamazepine $01(07 \%)$. Of 15,13 cases were having causality assessment as possible and remaining 2 cases as probable. Phenytoin was the most common drug with possible causality assessment to adverse drug reaction and was the only drug with probable causality assessment. Whereas, $5(33.33 \%)$ cases were serious of which $4(80 \%)$ of times were associated with phenytoin. $10(66.67 \%)$ of them were non-serious type of whom $7(70 \%)$ were due to phenytoin and $3(30 \%)$ were due to valproate. Most common type of adverse drug reaction encountered was giddiness $5(27.78 \%)$; followed by slurred speech $3(16.67 \%)$. Slurred speech was reported by 3 patients taking valproate, in one case, neurotoxicity was reported possibly due to carbamazepine (Figure 11).

Of 104 patients that were prescribed monotherapy, Phenytoin, $8(7.69 \%)$ were associated with an ADR. Similarly, out of 37 patients who were prescribed Valproate monotherapy, $2(5.4 \%)$ were associated with ADR. Likewise, of 12 patients on triple drug therapy regime (phenytoin+ carbamzepine+ valproate), 3 (25\%) patients developed ADR to combination. And, of 2 patients on phenytoin+ carbamazepine+ valproate+ levetiracetam combination, $1(50 \%)$ developed ADR. So, its apparent from the observation, that probability of adverse drug reaction occurring in epileptic patient increases, as no. of anti-epileptic drugs prescribed to patient increases (Table 2).

Table 2: Correlation of utilization pattern of AEDs with no. of adverse drug events.

\begin{tabular}{|c|c|c|c|}
\hline $\begin{array}{l}\text { Utilization of } \\
\text { AED (mono or } \\
\text { combination } \\
\text { therapy } \\
\text { prescribed) }\end{array}$ & $\begin{array}{l}\text { No. of } \\
\text { patient } \\
\text { prescribed }\end{array}$ & $\begin{array}{l}\text { No. of } \\
\text { ADR } \\
\text { (s) }\end{array}$ & $\begin{array}{l}\text { Suspected } \\
\text { anti- } \\
\text { epileptic } \\
\text { drug }\end{array}$ \\
\hline Phenytoin (PH) & 104 & $\begin{array}{l}08 \\
(7.7 \%)\end{array}$ & Phenytoin \\
\hline Valproate (VA) & 37 & $\begin{array}{l}02 \\
(5.4 \%)\end{array}$ & Valproate \\
\hline $\begin{array}{l}\text { Carbamazepine } \\
\text { (CRB) }\end{array}$ & 46 & $\begin{array}{l}01 \\
(2.2 \%)\end{array}$ & $\begin{array}{l}\text { Carbamaze } \\
\text { pine }\end{array}$ \\
\hline $\begin{array}{l}\text { Phenytoin+ } \\
\text { carbamzepine+ } \\
\text { valproate } \\
(\mathrm{PH}+\mathrm{CRB}+\mathrm{VA})\end{array}$ & 12 & $\begin{array}{l}03 \\
(25 \%)\end{array}$ & $\begin{array}{l}\text { Phenytoin- } \\
2 \\
\text { valproate-1 }\end{array}$ \\
\hline $\begin{array}{l}\text { Phenytoin+ } \\
\text { carbamazepine+ } \\
\text { valproate+ } \\
\text { levetiracetam } \\
\text { (PH+CRB+VA+ } \\
\text { LTR) }\end{array}$ & 02 & $\begin{array}{l}01 \\
(50 \%)\end{array}$ & Phenytoin \\
\hline
\end{tabular}




\section{DISCUSSION}

The study shows $320(88.64 \%)$ patients out of 361 from age group less than or equal to 60years. Other studies conducted in India shows identical age distribution with higher prevalence of epilepsy in age below 55yrs age. ${ }^{11,12}$ WHO has also mentioned similar findings in annual report in 2001 as it is more common in infancy and adolescence. ${ }^{13}$ $197(55 \%)$ volunteers were males while 164 (45\%) were females. Similar kind of information on gender distribution was obtained by Harron A et al, and Sigamani A et al, highlighting higher male: female ratio. ${ }^{11,14}$

Present study shows most common type of epilepsy was Generalized Tonic Clonic Seizures (GTCS) 152 (42\%) followed by focal seizures $88(24.38 \%)$. Similar finding was noticed by many studies highlighting that Generalized Tonic Clonic Seizures are common as compared to focal seizures. .,7,11,12 $^{2}$

Total 761 non anti-epileptic drugs were prescribed along with 593 antiepileptic drugs which constitutes to $56.2 \%$ of the total drug used. The most common supporting drug was folic acid 259 (34\%), Multivitamins preparations 84 (11\%) followed by calcium lactate $34(04.46 \%)$. Phenytoin and valproate are known to cause vitamin B12 and calcium deficiency which might results in megaloblastic anaemia and osteoporosis on prolonged use.

Present study highlighted that, phenytoin was the most common drug prescribed followed carbamazepine followed by valproate. Similar results were obtained by Mathur S el al. ${ }^{6}$ Some published studies (2002-2013) mention that valproate was the most commonly drug prescribed followed by Phenytoin or other drugs. ${ }^{7,15-19}$ A study published by Elizabeth ST et al, highlighted that phenobarbitone was the most commonly prescribed drug followed by phenytoin and valproate. ${ }^{20}$ A study from Singapore mentioned that carbamazepine was the most commonly drug prescribed followed by phenytoin and valproate. $^{21}$ An Italian study focused that levetiracetam was the most commonly drug used followed by carbamazepine $(34 \%)$ and lamotrigine, 18 in contrast to current study results where levetiracetam was $6^{\text {th }}$ most commonly drug prescribed and lamotrigine was not encounter even in a single prescription.

In present study usage of newer anti-epileptic drugs (02\%) was negligible as compared to older anti-epileptic drugs (98\%). Studies performed in abroad (Norway) mentioned equal19 or high uses of newer anti-epileptics. ${ }^{18}$ So far, no studies have shown that the newer drugs have superior anticonvulsant efficacy than conventional agents. In current study, $15(4.15 \%)$ cases of ADRs have been recorded in epileptic patients on AEDs. Most adverse drug reaction (ADR) was associated with Phenytoin in $11(73 \%)$ of cases followed by valproate $03(20 \%)$. In $5(33.33 \%)$ cases, ADR lead to hospitalization (serious ADRs) of patient, Phenytoin being responsible in $3(60 \%)$ of cases. No ADR was recorded from patients receiving newer anti- epileptic drugs like levetiracetam which signifies that their side effect profile is more favourable as compared to older conventional therapy. This may stand for a significant advantage in the treatment of a chronic disorder. It remains to be confirmed that this probable benefit outweighs the noticeably greater costs of "modern' anti-epileptic therapy. Most of the new agents have better pharmacokinetic properties than conventional antiepileptic drugs, including fewer interactions with other drugs. Wilbey et al, found that newer anti-epileptic drugs do not possess significant benefit in epilepsy outcomes compared with older AEDs. ${ }^{21}$

Total 192 (53\%) were on monotherapy and 169 (47\%) of them were on polytherapy i.e. on two or more Antiepileptic drugs. $111(31 \%)$ were on dual drug therapy, $53(15 \%)$ were on triple drug therapy, and $05(1.3 \%)$ were on quadruple drug therapy. This results are in conjuncture with other studies. ${ }^{6,7,8,15,17,22}$ which found that most of the patients $(\geq 50 \%)$ were prescribed single drug except one study performed by Malerba A et al, mentioned only $21 \%$ of the patients were prescribed Monotherapy. ${ }^{18}$ Guidelines mention that medical management of newly diagnosed epileptic patients should start with monotherapy. ${ }^{23}$ Polytherapy should be considered when there is failure of two attempts of monotherapy. Most of the patients i.e. 50$70 \%$ patients usually controlled on Monotherapy which formulate almost $30-50 \%$ patients refractory to monotherapy, which might need incorporation of more than or equal to two anti-epileptic drugs. ${ }^{24}$

Monotherapy is effective when clinician develops a tailored treatment plan that is suitably adapted for the individual patient, provides the patient with suitable education regarding the drug selected, and offers the chance for telephone follow-up and supervision with emergence of any adverse effects to allow timely feedback and modification of the titration scheme or target dose. ${ }^{25}$ Phenytoin was the most common drug $(51.56 \%)$ prescribed followed by carbamazepine $(46 \%)$. Similar result was obtained by Murthy $\mathrm{N}$ et al. ${ }^{17}$ Whereas foreign study Hanssens $\mathrm{Y}$ et al, mentioned that carbamazepine is commonly used as Monotherapy followed by phenytoin. ${ }^{15}$ phenytoin, valproate and carbamazepine are approved for Monotherapy for medical management of epilepsy. Levetiracetam is approved as adjunctive therapy in the treatment of Partial onset seizures, Myoclonic seizures as well as primary generalized tonic-clonic seizures. ${ }^{26}$ In contrast, present study found that Levetiracetam was used as monotherapy. Studies have supported the use of levetiracetam as monotherapy because it is well tolerated with only a small number of patients discontinuing the drug due to side-effects, with a favorable pharmacokinetic profile that includes minimal protein binding, lack of hepatic metabolism, and twice a day dosing. ${ }^{27-32}$

Irrespective of the AED use profile (both monotherapy and combination therapy) current study focused that the phenytoin was the most commonly prescribed drug for generalized tonic clonic epilepsy followed by valproate. 
The most common drug prescribed for simple partial seizure and complex partial seizure was carbamazepine. This is in contrast to study performed by Arulkumaran KSG. et al, which found that valproate was the most common drug prescribed for generalised tonic clonic convulsions followed by carbamazepine, phenytoin, lamotrigine and clonazepam. ${ }^{7}$

Current study results were also contradictory to study performed in Italy by Malerba A et al, mentioned that Valproate was the most commonly drug prescribed for GTC followed by lamotrigine and levetiracetam. ${ }^{18}$ While carbamazepine was the first line drug prescribed in simple partial seizures and complex partial seizures, although Phenytoin was used intermittently. Another Indian study by Elizabeth ST et al, mentioned that Phenobarbitone was most commonly drug prescribed for GTC followed by phenytoin and valproate. ${ }^{20}$ As per the ILAE guideline reviewed in 2013, all newly diagnosed patients should start with Monotherapy with 1st line anti-epileptic drugs which includes phenytoin, valproate, phenobarbitone and carbamazepine and should be continued depending upon the response, development of side effect or when maximum tolerated dose reached. ${ }^{33}$

The most common definition of polypharmacy is use of five or more drugs at the same time in the same patient. ${ }^{34}$ Average no. of drugs per encounter in epilepsy patients was $3.75 \pm 1.87$ (SD). Average no. of antiepileptic drugs (AEDs) per encounter in epilepsy patients was $1.64 \pm 0.78(\mathrm{SD})$, so the positive finding was that polypharmacy was obviously not present in study setting. The concurrent use of multiple drugs leads to increased chances of drug interactions and adverse drug reactions. ${ }^{35}$ So, the current practice at study site shows compliance to rational prescribing guidelines. A study conducted by Hasan $\mathrm{S}$ et al, mentioned that an average 1.51 antiepileptic drugs per patient were prescribed. ${ }^{36}$ Out of $361,15(4.16 \%)$ patients reported with ADR related to antiepileptic drugs. This finding was similar to study by Mathur et al. ${ }^{6}$ Most adverse drug reaction (ADR) was associated with Phenytoin in $11(73 \%)$ of cases followed by valproate 03 (20\%) and carbamazepine $01(07 \%)$. Most of these correspond well with the known adverse effect profile of phenytoin. ${ }^{37}$ Slurred speech was reported by 3 patients taking valproate, of which $2(66.66 \%)$ patients were on monotherapy. In one case, neurotoxicity was reported possibly due to carbamazepine.

\section{CONCLUSION}

This study suggests that newer drugs should be made available at hospital drugs list. Current study also found the need of creating awareness amongst treating physician about pharmacovigilance for ADR signal detection.

\section{ACKNOWLEDGEMENTS}

Authors would like to thank to Department of General Medicine of Institute for granting permission for the study.
Funding: No funding sources

Conflict of interest: None declared

Ethical approval: The study was approved by the Institutional Ethics Committee (BJGMC/IEC)

Pharmac/D-1115146-146)

\section{REFERENCES}

1. Lowenstein DH. Chapter 445, Seizure and epilepsy. Harrison's principles of internal medicine, 19th ed. USA: McGraw Hill.2015:2542-2559.

2. Banerjee T K, Ray B K, Das S K. A longitudinal study of epilepsy in Kolkata, India. Epilepsia. December 2010;51(12): 2384-91.

3. Meyer AC, Dua T, Ma J, Saxena S, Birbeck G. Global disparities in the epilepsy treatment gap: a systematic review. Bull World Health Organization. 2010;88:260-6.

4. Cloyd JC, Remmel RP. Antiepileptic drug pharmacokinetics and interactions: impact on treatment of epilepsy. Pharmacotherapy: J Human Pharmacol Drug Therapy. 2000 Aug;20(8P2):139S51S.

5. Foletti GB. Clinical utilization of new anti-epileptic agents. Rev Med Suisse Romande. 2000 Sep;120(9):703-7.

6. Shobhana M, Sumana S, Ramesh L, Satish Kumar M. Utilization pattern of antiepileptic drugs and their adverse effects in a teaching hospital. Asian $\mathbf{J}$ Pharmaceut Clin Res. 2010;3(1):55-9.

7. ArulKumaran K, Palanisamy S, Rajasekaran A. A Study on drug use evaluation of antiepileptic drugs at multispeciality tertiary care teaching hospital. Int $\mathbf{J}$ PharmTech Res. 2009;1(4):1541-7.

8. Chen LC, Chen YF, Yang LL, Chou MH, Lin MF. Drug utilization pattern of antiepileptic drugs and traditional Chinese medicines in a general hospital in Taiwan-a pharmaco-epidemiologic study. J Clin Pharm Therapeut. 2000 Apr;25(2):125-9.

9. Radhakrishnan K, Nayak SD, Kumar SP, Sarma PS. Profile of antiepileptic pharmacotherapy in a tertiary referral center in South India: a pharmacoepidemiologic and pharmacoeconomic study. Epilepsia. 1999 Feb;40(2):179-85.

10. Lammers MW, Hekster YA, Keyser A, Meinardi H, Renier WO, Van Lier H. Monotherapy or polytherapy for epilepsy revisited: a quantitative assessment. Epilepsia. 1995 May;36(5):440-6.

11. Haroon A, Tripathi M, Khanam R, Vohra D. Antiepileptic drugs prescription utilization behaviour and direct costs of treatment in a national hospital of India. Ann Indian Acad Neurol. 2012;15(4):289-93

12. Pal A. Drug utilization pattern of antiepileptic drugs: a pharmacoepidemiologic and pharmacovigilance study in a tertiary teaching hospital in India. Asian J Pharmaceut Clin Res. 2011;4(1):96-9.

13. World Health Organization. Social consequences and economic aspects: fact sheet N.166. Geneva: World Health Organization, 2001), (ILAE/IBE/WHO. "Out of the shadows": global campaign against epilepsy. 
ILAE/IBE/WHO Annual Report, Geneva: World Health Organization, 1999.

14. Sigamani A, Roy AK, Yeragani VK, Kulkarni C. Profile of pharmacotherapy and pharmacoeconomics of epilepsy treatment at a tertiary care hospital. Ann Neurosci 2006;13:103-12.

15. Hanssens Y, Deleu D, Al Balushi K, Al Hashar A, AlZakwani I. Drug utilization pattern of anti-epileptic drugs: a pharmacoepidemiologic study in Oman. J Clin Pharm Ther. 2002 Oct;27(5):357-64.

16. Pathak S. Prescribing patterns of Anti-epileptic drug in different age group in India. J Drug Discovery Therapeut. 2013 Jul 21;1(07).

17. Murthy NV, Anusha B, Perumal P. A Study on trends in prescribing pattern of anti-epileptic drugs in teritiary care teaching hospital. Int J Che Pharmace Sci. 2012;3(2):25-30.

18. Malerba A. Patterns of prescription of antiepileptic drugs in patients with refractory epilepsy at tertiary referral centres in Italy. Available at: http ://pharmacy. oregonstate. Edu /drug_ policy /sites/default /files /pages/ dur_board /evaluations /articles/2011_05_aed_due.pdf. Accesses 4 November 2017.

19. Landmark CJ, Fossmark H, Larsson PG, Rytter E, Johannessen SI. Prescription patterns of antiepileptic drugs in patients with epilepsy in a nation-wide population. Epilepsy Res. 2011 Jun;95(1-2):51-9.

20. Elizabeth ST, Kia RA, Yagnik RM, Nagaraju K. Prescribing Pattern of Antiepileptic Drugs in Adults in a South Indian Tertiary care Hospital. Indian J Pharmacy Practice. 2012;5(1):52-6.

21. Wilbey J, Kainth A, Hawkins N, Epstein D, McIntosh $\mathrm{H}$, McDaid C, et al. Clinical effectiveness, tolerability and cost-effectiveness of newer drugs for epilepsy in adults: a systematic review and economic evaluation. Health Technol Assess. 2005 Apr; 9(15):1-157.

22. Hui S. Pattern of antiepileptic drug usage in tertiary referral hospital in Singapore. Neurol J Southeast Asia. 1997;2:77-85.

23. Guidelines for the management of epilepsy in India. Indian epilepsy society. 2008. Available at: http://www.epilepsyindia.org/ies/GUIDELINES/Gem ind_Combine.pdf. Accessed 18 October 2017.

24. Gupta V, Gupta DM, Gupta R. Intractable epilepsy. JK-Practioner. 2005;12(2):105-7.

25. Lous EK, Rosenfeld WE, Branley T. Antiepileptic drug monotherapy: the initial approach in epilepsy management. Curr Neuropharmacol. 2009 June;7(2):77-82.

26. Levetiracetam. Available at: website http://www. accessdata. fda. gov/ drugs at fda_docs /label/ 2013
/021035 s089, 021505s030lbl.pdf. Accessed 10 October 2017.

27. French JA, Kanner AM, Bautista J. Efficacy and tolerability of the new antiepileptic drugs I: treatment of new onset epilepsy. Neurol. 2004a;62:1252-60.

28. French JA, Kanner AM, Bautista J, et al. Efficacy and tolerability of the new antiepileptic drugs II: treatment of refractory epilepsy. Neurol. 2004b; 62:1261-73.

29. Alsaadi T, Thieman C. Levetiracetam monotherapy for newly diagnosed epilepsy patients. Seizure. 2003;12(3):154-6.

30. Gambardella A, Labate A, Colosimo E, Ambrosio R, Quattrone A. Monotherapy for partial epilepsy: focus on levetiracetam. Neuropsychiatr Dis Treat. 2008;4(1):33-8.

31. Karceski S, Morrell MJ, Carpenter D. Treatment of epilepsy in adults: expert opinion. Epilepsy Behav. 2005;7:S1-S64.

32. MacNeil JS. Levetiracetam Effective Monotherapy for Epilepsy 2003. Available at: http://www.medscape .com/ view article /465702. Accesses 18 September 2017.

33. Glauser T, Ben-Menachem E, Bourgeois B, Cnaan A, Guerreiro C, Kälviäinen R, et al. Updated ILAE evidence review of antiepileptic drug efficacy and effectiveness as initial monotherapy for epileptic seizures and syndromes. Epilepsia. 2013 Mar;54(3):551-63.

34. Werder SF, Preskorn SH. Managing polypharmacy: Walking the fine line between help and harm. Curr Psychiatry Online. 2003 Feb;2(2):24-36.

35. Lawthom C. Polytherapy and epilepsy: what is the role of polytherapy in the treatment of epilepsy?. Available at: website. http://rc.kfshrc.edu.sa/rcf/E_Library/Epilepsy/Polythe rapy.pdf. Accesses 4 September 2017.

36. Hasan SS, Bahari MB, Babar ZU, Ganesan V. Antiepileptic drug utilisation and seizure outcome among paediatric patients in a Malaysian public hospital. Singapore Med J. 2010 Jan 1;51(1):21.

37. Desai JD. Epilepsy and cognition. J Pediatr Neurosci. 2008 Jan 1;3(1):16.

Cite this article as: Magar YB, Hiray RS, Ghongane BB. Utilization pattern of antiepileptic drugs and their adverse effects in tertiary healthcare and teaching hospital. Int J Basic Clin Pharmacol 2019;8:39-46. 